\title{
Ethnic Diversity and School Leadership: Lessons from Johannesburg Schools
}

\author{
Annastacia Buma \\ Pierre du Plessis
}

University of Johannesburg

Email pierredp@uj.ac.za

\section{Doi:10.5901/mjss.2014.v5n20p1184}

\begin{abstract}
Increasingly, South African schools are becoming more diverse due to the implementation of new legislation to foster democratization in schools. Other external factors such as increasing globalization may also be contributing to the apparently growing diversity at schools. Such increasing diversity could pose challenges regarding fostering a culture of teaching and learning at these integrated schools. Therefore, this article looks at how school management and leadership are fostering a culture of teaching and learning in ethnically diverse schools in Johannesburg North District. The theoretical perspectives for this study are based on multicultural education and diversity. The study is embedded in a social constructivist inquiry paradigm. It reports on the application of a mixed method design which aims at capturing the lived experiences, beliefs and feelings of the participants who are the principals, Heads of Departments (HoDs), teachers and learners, as expressed in their languages, both spoken and written in relation to ethnic diversity. The data collected, show that the diverse cultures of schools in Johannesburg North include characteristics of both traditional and liberal multicultural education and illustrate the fact that societies are becoming more complex in terms of social, economic and political composition. Therefore, in addition to teaching the basic skills of reading, writing and math, school leadership and management should encourage teaching and learning that will involve social justice issues, equity and equality through which students will learn to become reflective, moral, caring and active citizens, goals which liberal multicultural education aims to achieve.
\end{abstract}

\section{Introduction}

Increasingly, South African schools are becoming more diverse due to the implementation of new legislation to foster democratization in schools. Other external factors such as increasing globalization may also be contributing to the apparently growing diversity at schools. Such increasing diversity could pose challenges regarding fostering a culture of teaching and learning at these mixed schools. Therefore, this study is based on ethnically diverse schools in South Africa, specifically in Johannesburg North District. Since students and pupils from different ethnic groups are attracted to the schools in this area, it is imperative that the leadership and management of these schools come up with efficient measures to assist in managing demographic changes in a manner that will foster a culture of teaching and learning that will benefit the diverse learner body (Meier \& Hartell, 2009:180). The purpose of this research is to examine how school leadership and management in ethnically diverse schools create and maintain a culture of teaching and learning at the schools

In the context of this study, ethnic diversity refers to the existence of a variety of learners in terms of ethnicity, nation, race, culture, language and social class with resulting implications on teaching and learning (Lemon, 2008:303). The changes that are associated with the increasing ethnic diversity in schools have placed tremendous demands on school principals (Leeman, 2003:43; Meier \& Hartell, 2009) and teachers (Vandeyar, 2010: 346) that have to deal with a number of unique challenges. Some of these challenges include culture mismatch within student-student and studentteacher interaction, social tension and antagonism, communication problems, misinterpretation of values and behaviour that influence the process of teaching and learning (Banks \& Banks, 2005:12; Borman, Baber, \& Associates, 1998; Carignan, Pourdavood, King \& Feza, 2005; Gay, 2000:54).

Having worked in both private and public schools in South Africa over the last ten years, the researcher has observed significant changes in the demographic composition of learner populations across many schools ( especially the 'ex Model C' schools located within or near the city centre), where the medium of instruction is English (Le Roux, 2000:2; Vandeyar, 2010: 345). The dimensions of the changing demographics include race, language, ethnicity, nationality and economic background (Boutte, 1999:17). Although some changes have also occurred in the composition of the staff 
bodies of schools, this appears to have been minimal when compared to changes in the learner body (Carignan, et al 2005:382; Lemon, 2008:305).

In addition, casual observation suggests that across South Africa, more and more non-Black African (White, Indian and Coloured) dominated staff teams now have to deal with more and more Black African dominated learner bodies (Carignan, et al. 2005: 381; Lemon, 2008: 309). Thus, the composition of learner populations has changed but that of teachers remain more or less the same, a situation that poses a likely source of conflict. This situation has been identified in some British schools where it is associated to huge differences between learner and teacher populations in terms of culture (Verma, et al. in Wedekind, 2001:147). Similarly, a lack of representation among the teaching staff, of the different cultures within the student body, combined with teachers not being well prepared to deal with these changes, serve as possible causes of poor performance among both educators and learners. As a result of the increasing diversity in schools today, school leaders must create and promote opportunities that will foster a culture of teaching and learning at the schools, taking into consideration the need to value the diverse nature of the school.

\section{Methodology}

This study employed a mixed method research design making use of qualitative and quantitative methodologies. The mixed method design allow for qualitative and quantitative inquiry which provide room for logical groups of methods to be used to obtain data for a set of interpretative practices without privileging any individual methodologies over others (Denzin and Lincoln, 1998:2). And therefore, the employed data collection methods that were necessary to the purpose of the study include; questionnaires, in depth semi structured interviews and document review that not only complement one another but also enhance the legitimacy of the information provided by each participant.

\subsection{Sampling}

In this study, the population is the participants and objects of ethnically diverse schools in Johannesburg north District with the units of analysis being the principals, HODs, teachers and learners. This study, thus, utilize purposeful sampling because the researcher intentionally selected individuals and sites which provided data containing the information that was needed to get an in-depth understanding of the perceptions, feelings and experiences of school management and leadership in fostering a culture of teaching and learning in four ethnically diverse schools in Johannesburg north district (Marshall \& Rossman1999:73; Mills, 2003: 61; Zikmund, 2003: 373).

In recognition of the above, the researcher meticulously selected four ethnically diverse schools - two primary and two high schools - in Johannesburg North district and from each school, the principals and there HODs filled in carefully proof read questionnaires. Three teachers and four learners were interview in each school. Hence, the study involved a total of 44 participants. Teachers with varying degree of experiences at the schools were selected. While some had ten years or more of experience, others had no more than three. The selected teachers and learners were from different ethnic groups including Black African (South African and non- South African, Coloured, Indian and white backgrounds. This was a strategy to generate a rich and diverse data.

\subsection{Data collection}

Data was collected through primary and secondary data collecting instruments. The primary involved two sets of questionnaires labeled 1 and 2 that were handed over to the principals of the four schools. The first one named Questionnaire 1 aimed at getting general information about the schools in terms of the learners and staff population records over a period of ten years as well as the composition of major teams, including sports and cultural activities, representing each school. The second one named Questionnaire 2 was directed to the principals and HoDs. The aim of this questionnaire was to obtain information on the perceptions, feelings and experiences of school leaders of ethnically diverse schools in advancing a culture of teaching and learning in their schools. Only one of the four schools managed to complete the questionnaires and forms within the two weeks requested with no reason given for the delay. Eventually, it took a little over two months to get back the completed questionnaires and some of the requested documents back from all the schools.

Twenty-eight participants were interviewed consisting of three teachers and four learners from the four schools. The researcher used an interview guide consisting of a set of predetermined open-ended questions to guide the line of inquiry during the in-depth constructionist individual interviews. The recorder used in this study help to produce high quality transcripts that served as primary data for eventual analysis. 
The questionnaires were completed by four respondents from each of the selected schools and all respondents have been kept anonymous on request, and for the purpose of this study, the assigned numbers 1, 2, 3 and 4 represent each respondent from each of the schools. Similarly, the four schools are designated as A, B, C and D.

Secondary data was collected as the researcher made use of learner population records and the school policy documents that included language policy, discipline, learner recruitment, staff recruitment and diversity management policies for all four schools to establish how diversity is addressed in the vision and mission statements of the schools (Boutte, 1999: 323)

\subsection{Data analysis}

Qualitative analysis of the data was performed largely by drawing comparisons or contrasts between evidence from the field survey and the literature review as well as drawing inferences from responses from the various schools or individual respondents. The three perspectives of multicultural education as identified by the researchers such as Banks and Banks (2005: 22) and Hoffman and McLaren (cited in Carignan et al. 2005: 382) constitute an important theoretical framework for the analysis of data in this study. I addition, the researcher used the three-step coding grounded theory strategies (Henning, Van Ransburg \& Smith, 2004: 131) to encode the data gathered from both interview transcripts and questionnaires to derive themes which are presented in the table below

Table 2.1: Summary of themes and sub-themes derived from the data

\begin{tabular}{|l|l|}
\hline Theme & Sub-themes \\
\hline Cultural diversity & Cultural diversity of school participants \\
\hline Language of instruction & English as language of instruction \\
\hline Teaching methods & Appropriate teaching methods \\
\hline Diverse Curriculum & $\begin{array}{l}\bullet \text { Suitability of current curriculum } \\
\bullet \text { Challenges within the current curriculum } \\
\text { - Changes suggested within the current curriculum }\end{array}$ \\
\hline Diversity policy & Changes suggested within the schools policies \\
\hline
\end{tabular}

The three perspectives of multicultural education as identified by the researchers such as Banks and Banks (2005: 22) and Hoffman and McLaren (cited in Carignan et al. 2005: 382) constitute an important theoretical framework for the analysis and interpretation of data in this study. The three perspectives and their distinctive characteristics have been arranged in the table below. Table 2.2: Characteristics of the three perspectives of multicultural education (ME)

\begin{tabular}{|c|c|c|c|c|}
\hline Traditional ME & Libe & eral ME & $\operatorname{Rad}$ & ical ME \\
\hline 1) Regards culture as fixed (T1) & 1) & Accommodates change through & 1) & Seeks to stop oppression and injustices.(R1) \\
\hline 2) Promotes racism (T2) & & curriculum reforms (L1) & 2) & Promotes education which addresses the needs of \\
\hline 3) Superior universal culture(T3) & 2) & Acknowledges multiple identities(L2) & & diverse cultural groups.(R2) \\
\hline $\begin{array}{l}\text { 4) Perpetuation of the established } \\
\text { groups hegemony (T4) }\end{array}$ & 3) & $\begin{array}{l}\text { Combats discrimination based on ethnic } \\
\text { differences (L3) }\end{array}$ & 3) & $\begin{array}{l}\text { Attempts to resist capitalist values relating to blind } \\
\text { mass consumption of a dominant view that }\end{array}$ \\
\hline 5) Reproduction of mainstream & 4) & Promotes cultural pluralism. & & supports inequality.(R3) \\
\hline society's norms and values (T5) & 5) & Culture is dynamic and flexible(L5) & 4) & ession of one group by another.(R4) \\
\hline $\begin{array}{l}\text { 6) Undermines the cultures of the } \\
\text { minority groups. (T6) }\end{array}$ & 6) & $\begin{array}{l}\text { Interrogates discrimination based on } \\
\text { physical/ethnic differences, }(\mathrm{L} 6)\end{array}$ & 5) & $\begin{array}{l}\text { Reflects the concerns of diverse cultural groups. } \\
\text { (R5) }\end{array}$ \\
\hline $\begin{array}{l}\text { 7) Culture is viewed as unchanging } \\
\text { and the world is as it is.(T7) }\end{array}$ & 7) & $\begin{array}{l}\text { Supports diversification of curriculum } \\
\text { (L7) }\end{array}$ & 6) & $\begin{array}{l}\text { It involves students in democratic decision making. } \\
\text { (R6) }\end{array}$ \\
\hline & 8) & Adapting teaching styles (L8) & 7) & Involves minority parents in school and local \\
\hline & 9) & Perceives the world as being sensitive to & & community action projects.(R7) \\
\hline & & development. (L & 8) & Promotes diverse racial, gender and disability \\
\hline & 10 & Accommodates social diversity. & & grouns in non-traditional \\
\hline & 11 & Promotes individual and collective & 9) & Takes on a reconstructivist perspective(R9) \\
\hline & & & 10) & \\
\hline & 12) & Opposes oppression(L12) & & \\
\hline & 13) & Promotes tolerance and acceptance. & 11) & Denunciates injustice and oppression (R11) \\
\hline & & $(\mathrm{L} 13)$ & 12) & $\begin{array}{l}\text { Favours communication relations, interaction and } \\
\text { interdependency among cultures.(R12) }\end{array}$ \\
\hline
\end{tabular}

To enhance the data presentation and analysis, the characteristics presented on Table 2.2 have been numbered and the 
letter at the beginning of each perspective will be used together with the assigned number of each characteristic when it is being referred to. For example, the first characteristic for traditional, liberal and radical multicultural education will be referred to as T1, L1 and R1 respectively.

\section{Results}

The study found that in all four schools, both learner and teaching staff population is becoming increasingly diverse, although the change is more evident with learner's population which has a fairly high number of the previously disadvantage groups as well as students from other African countries. Hence, the demographic composition of teachers and learners that were gotten from each school over a period of ten years are presented in the following figures below,

Figure 3.1: Learner population group distribution for School $A$

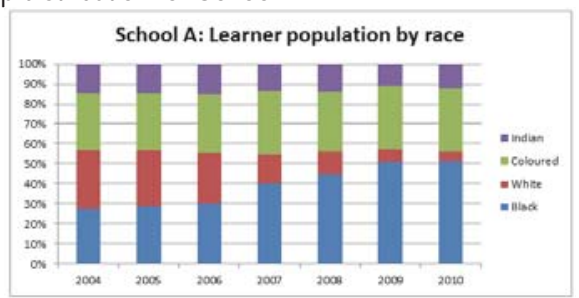

Figure 3.2: learner population group distribution by race

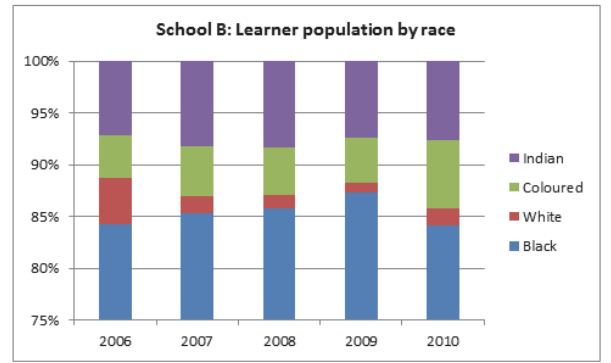

Figure 3.3: learner population group distribution by race from 2000-2010

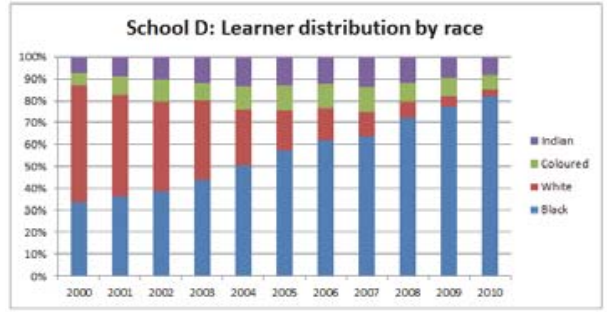

Figure 3.4: Staff population group distribution for school A

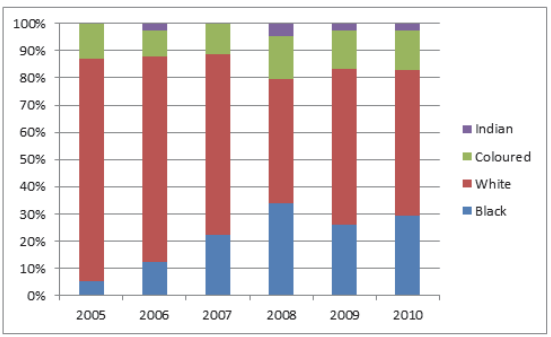


Figure 3.5: Staff population group distribution for school D by race (2005- 2010)

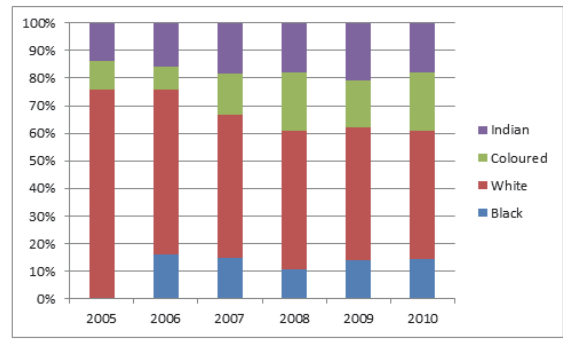

A discussion was presented based on the five themes and the three perspectives on multicultural education. Through indepth examination of the data, the researcher identifies some factors from each school which relate to the three perspectives of multicultural education as well as the derived themes namely cultural diversity, diversity policy, diverse curriculum, language of instruction and teaching methodologies that could influence the way in which teaching and learning is experienced at the school. This part of the discussion made extensive use of quotes from the raw data as evidence presented below.

\section{Cultural Diversity}

Most of the participants of all the schools $(A, B, C, D)$ share a common perception that cultural diversity is being promoted at the schools. Most of the school leaders share this view which is supported by the response from the teachers and students. This is evident from the following quotes. Quotes from questionnaire survey:

\section{Response School A:}

1. Learners learn about other cultures. They interact together as 1 group

2. They are taught in a micro-cosmos which is a reflection of the community. Socialization with other cultures. Learners have fewer cultural issues than their parents.

\section{Response from school C:}

Quotes from questionnaires Survey:

1. We discuss with learners the diversity of various cultures. We teach learners to respect the other cultures. All learners are welcomed to our school by teachers, management and learners.

2. Anti-bullying campaigns. Allowing for diverse in cultureslreligions.

However, some participants from school B expressed that although staff and student diversity is encouraged in their school, there are negative implications for teaching and learning due to language barriers and cultural differences. This is evident from the following quotes. Quotes from interview survey:

\section{School B Staff : Response}

It means if certain group has got a particular negative view, towards another ethnic group $A B C$, then it means that impression, that prejudice will be translated even into learning.

One interviewee from School $\mathrm{C}$ is of the opinion that the teaching staff is not really diverse. She feels that more has to be done to increase staff diversity as evident in the following quotes. Quotes from interview survey

\section{School C Staff : Response}

For staff diversity, we need to be more aware of what each culture is all about and you know we do not have a lot of diversity in the staff, as well but we always ask ourselves " if you were in the same situation, what would you do?" so that we can solve the problem in the class room

One interviewee of school $D$ is of the opinion that, in terms of staff diversity adults are not really tolerant of each other's differences. She feels that more has to be done to increase awareness and tolerance among the diverse staff team as the quote below reveals. Quotes from questionnaires survey: 


\section{School D:}

3. Adults are less tolerant of our diversity.

On the contrary, responses from some other students indicate that most of them are interested to know more about the cultural backgrounds of their teachers or fellow students. They are more tolerant and believe that cultural diversity is good and should be appreciated as this enhances learning. Additionally, they seem to have no problems mixing with teachers and students from different backgrounds. This is evident from the following quotes:

\section{School D Students: Participant A}

Quotes from interview survey

I don't have any issue with that because we are a rainbow nation and have to like everybody.

\section{Student: Participant D}

No, there are no challenges.....no problem..... I leant how they greet, what food they eat, and other

things that they're reading and stuff like that.

\section{Language of Instruction}

In all the schools, information obtained from the study of language policy of the school corresponds to the views of the school leaders and those of teachers and students from the interview survey. According to the language policy, English language is the main medium of instruction although the school participants communicate in multiple home languages other than English. This implies the absence of opportunities to cater for the developmental needs of the mother tongues of some students. These opportunities which are absent in all the Schools constitute an important aspect of traditional multicultural education. Refer to Table 2.2 (see T3, T4, and T6),

Most participants feel that English language prevents effective communication, and that this constitutes a barrier to learning as some students struggle with basic reading and writing skill. This is evident from the quotes below. Quotes from questionnaires survey:

\section{Response School B:}

1. Main challenge concerns the background of the learner. Not all learners have been exposed to English FL as medium of instruction.

2. Communication sometimes a problem.

\section{School: B : Staff participant B}

Quotes from interview survey:

I think the language barrier is sometimes difficult with English being used as the main media when it is not most of the people's first language.

\section{School D Staff : participant C}

\section{Quotes from interview survey}

......some children are struggling in English because they are not speaking it at home and maybe some of them, their parents cannot help them in English because they don't know English.

\section{Staff: Participant D}

....communication, our medium of communication is English ...... The biggest problem is the foreign learners because I think that they constitute a majority of our school population. It's that we do not have a bridging class as such and communication, our medium of communication is English..... ALL the learners are taught in English

\section{Teaching Methods}

A number of participants including school leaders, teachers and students from all four schools feel that interactive pedagogy is being implemented at their school to foster the culture of teaching and learning. They feel that students are being motivated to interact and learn through sports, cultural day activities, group work, and arts festivals. These interactions lead to cooperative teaching and learning where teachers, learners and the parents are involved in order to provide support to learners. This is evident from the following quotes: 


\section{Response :School A:}

Quotes from Questionnaires survey:

1. Learners participate in sports and classroom discussions. They speak about their differences.

3. Multicultural classes, bilingual classes - we cater for different cultures with different sports codes e.g. soccer.

\section{School A : Staff : Participant A}

Quotes from interview survey:

Well, I think that it positively influences our school whereby we learn from one another. We are more open to one another. We are not restrictive to a certain group. ....We learn from one another and it makes learning a whole lot more fun and interesting and we learn different perspectives.

\section{Participant D}

.... Like if you look at the White children and the African children and the Coloured in this school, they all mix well together which I think is positive.

However, two participants from school B expressed that nothing is being done in their school to encourage cross-cultural learning and that the onus is on individual learners to do so. They also believe that learners have had pre-exposure to such experiences hence the school does nothing in this regard. The following quotes illustrate these opinions:

\section{School B Response}

Quotes from Questionnaires survey

1. Nothing done to encourage it consciously. Perhaps learners have been exposed to a diverse schooling environment in primary school already.

3. Not really encouraged- left up to the individuals

\section{Diverse Curriculum}

Some of the other participants believe that the current curriculum is suitable for teaching and learning. This is because it promotes diversity as it represents the diverse culture of the school participant. These ideas are evident from the following quotes:

Quotes from interview survey:

\section{School A Staff: participant A}

Ok is it suitable like the curriculum, deals with the cultures of the learners which is represented in our curriculum.

It is suitable for the learner population.

\begin{tabular}{l} 
Quotes from Questionnaires survey \\
School B Response \\
1. Very inclusive and addresses the imbalances of the past. \\
3. The curriculum allows for different approaches. \\
\hline
\end{tabular}

Although most of the participants from all School $(A, B, C, D)$ share a common perception that the current curriculum needs to be improved, the area of concern was different from one participant to the other. This is evident from the following quotes:

\section{Response School A:}

Quotes from Questionnaires survey:

1. Content that is relevant to everyday life of learners, dealing with obstacles in their life.

2. I believe that ethnicity should not be necessarily taken into consideration in curriculum changes.

3. Teacher admin must be reduced, then the other challenges will become irrelevant

4. The learners should study more for tests, exams in order to broadened their intelligence. Information should be digested and not forgotten when they leave the class. 
Quotes from Questionnaires survey

\section{Response School B:}

1. Strong emphasis on language and mathematics in primary schools as part of the foundations for learning programme.

2. Higher and standard grade.

3. More content learning. Less exploratory learning especially grades 8 and 9

4. Teaching should be more technological based than the present situation.

\section{Discussion}

Upon analysing the data under the rubrics of the five themes and within the context of the liberal, traditional and the radical perspectives of multicultural education, one of the key findings reported in this study is that all the schools involved in the study are practicing liberal multicultural education. However, each school exhibits some of the distinctive features of traditional multicultural education especially with regards to their use of English as language of instruction (see T5 on Table 2.2). Hence, using a Venn diagram synthesized by the researcher from the above three perspectives, it is possible to position the schools according to the dominant perspective assumed by its leaders (see Figure 3.1 below).

Figure $3.1 \quad$ Perspectives of multicultural education synthesized by the researcher from the literature according to the researchers (Banks \& Banks (2005: 22); Hoffman \& McLaren (in Carignan, et al. 2005:

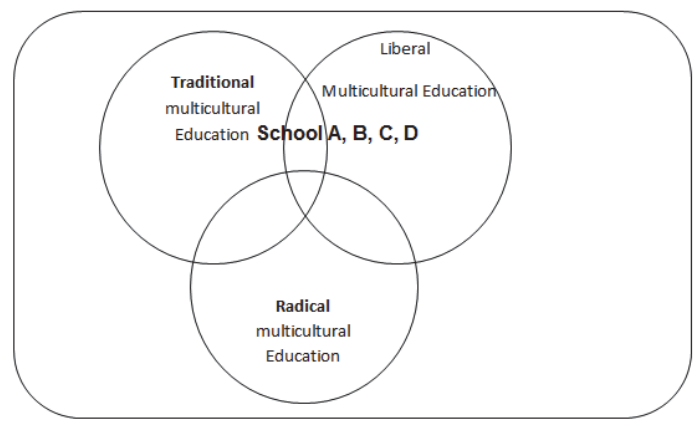

The research indicates that generally, schools do not want to open up on issues relating to diversity. This may be attributed to the fact that transformation is not taking place or not given much attention at the schools and Meier and Hartel, (2009:181) suggest that schools need to speed up the process of change in order to providing teaching and learning opportunity that will benefit the diverse school population. They further refer to the attempt by schools to encourage diversity through celebratory approaches as superficial and thus maintain the state of affairs as meaningful learning opportunity is provided to a few.

Similarly, Cross (2001:391) argued that during the apartheid era, discrimination was enforced on the basis of diversity and that the negative consequences have persisted since then. This may be the reason why some schools and specifically some leaders do not want to encourage research studies that have to do with issues of diversity.

\section{Conclusions}

On the basis of the extensive findings of this research, the researcher was to make the following conclusions regarding school leadership and management experiences in fostering a culture of teaching and learning at their schools. The diverse cultures of schools in Johannesburg North include characteristics of both traditional and liberal multicultural education and illustrate the fact that societies are becoming more complex in terms of social, economic and political composition and therefore, in addition to teaching the basic skills of reading, writing and math, school leadership and management should encourage teaching and learning that will involve social justice issues through which students will learn to become reflective, moral, caring and active citizens, goals which liberal multicultural education aims to achieve.

The school leadership and management of ethnically diverse schools in Johannesburg North district are engaged in promoting cultural assimilation as English language is being used as the dominant medium of instruction, preventing effective communication and constituting a barrier to teaching and learning. The school Leadership and management of ethnically diverse schools have the responsibility of creating the appropriate atmosphere in terms of school culture, policy and curriculum required to advance a culture of teaching and learning that should benefit the diverse population. Hence, 
the researcher believes that by applying the recommendations in this study, school leaders would be able to advance opportunities to enhance the culture of teaching and learning in their schools. Therefore, the researcher recommends that: more effort should be made to diversify the profile of teaching cops. Professional teacher development programs should include diversity initiatives that could effectively benefit all learners.

Regular surveys should be carried out in ethnically diverse schools to increase awareness of the positives of diversity through establishing a data base that could easily be accessed by all stakeholders in ethnically diverse schools. The national and provincial department of education should design training programs aim at developing leadership and management as well as other staff members towards advancing a culture of teaching and learning through liberal multicultural education in ethnically diverse schools.

\section{References}

Banks, J. \& Banks, C. (Editors). (2005). Multicultural Education: Issues and perspectives. USA : John Wiley \& Sons.

Borman, K.M., Baber, M.Y. \& Associates. (1995). Ethnic Diversity in Communities and Schools: Recognizing and Building on Strengths. UK: JAI Press Ltd.

Boutte, G. (1999). Multicultural Education: Raising Consciousness. Belmont, CA: Wadsworth publishing company.

Carignan, N., Pourdavood, R.G., King, L.C. \& Feza, N. (2005). Social Representation of Diversity: Multi/intercultural Education in South African Urban School. Intercultural Education 16(4): 381-393.

Cross, M. (2004). Institutionalizing Campus Diversity in South African Higher Education: Review of Diversity Scholarship and Diversity. Education. Higher Education. 47: 287-410.

Denzin, N.K. \& Lincoln, Y.S.( ed) (2008). Collecting and Interpreting Qualitative Materials. California: Sage Publications.

Gay, G. (2000). Culturally Responsive Teaching: Theory, Research and Practice. New York: Teachers College Press.

Leeman, Y. \& Reidb, C. (2006). Multi/intercultural education in Australia and Netherlands. Compare, 36(1): 57-72.

Lemmer, E.M. (2002) Fostering Language development in multicultural schools in South Africa. S.A Publications, 31(1-2):38-62. http:0www.journals.co.za. Ujlink.uj.ac.za.Accessed 9 October 2010.

Lemon, A. (2008). Indian identities in the 'rainbow nation': Response to transformation in South African schools. National identities, 10 (3): 295-312.

Le Roux J. (2000). Multicultural education: a new approach for a new South African dispensation. Intercultural Education, 11(1): $19-29$.

Marshall, C. \& Rossman, G. B. (1999). Designing Qualitative Research. ( $3^{\text {th }}$ Edition). California: Sage Publication.

Meier, C. and Hartell, C. ( 2009). Handling cultural diversity in education in South Africa. SA-eDUC JOURNAL , 6( 2):180 - 192.

Mills, G. E. (2003). Action Research: A Guide for the teacher Research. (2nd edition). Columbus: Merill Prentice Hall.

Vandeyar, S.(2010). Responses of South African teachers to the challenge of school integration. South African Journal of Education, 30:343-359.

Wedekind, V.R ( 2001). Teachers, the South African State, and the Desegregation of Schools in the 1990s. In Ethnicity, Race, and Nationality in Education. Edited by

Zikmund, W.G. (2003). Business research methods. Ohio: Southern-Western 